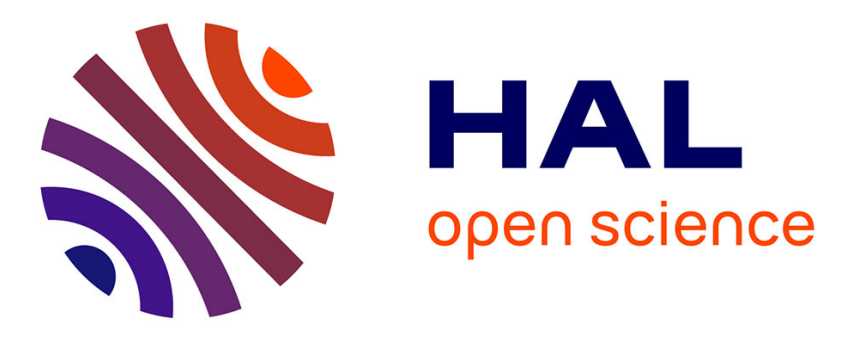

\title{
Effect of dispersed crude oil exposure upon the aerobic metabolic scope in juvenile golden grey mullet (Liza aurata)
}

Thomas Milinkovitch, Julie Lucas, Stéphane Le Floch, Hélène

Thomas-Guyon, Christel Lefrançois

\section{To cite this version:}

Thomas Milinkovitch, Julie Lucas, Stéphane Le Floch, Hélène Thomas-Guyon, Christel Lefrançois. Effect of dispersed crude oil exposure upon the aerobic metabolic scope in juvenile golden grey mullet (Liza aurata). Marine Pollution Bulletin, 2012, 64, pp.865-871. 10.1016/j.marpolbul.2012.01.023 . hal-00690508

\section{HAL Id: hal-00690508 https://hal.science/hal-00690508}

Submitted on 23 Apr 2012

HAL is a multi-disciplinary open access archive for the deposit and dissemination of scientific research documents, whether they are published or not. The documents may come from teaching and research institutions in France or abroad, or from public or private research centers.
L'archive ouverte pluridisciplinaire HAL, est destinée au dépôt et à la diffusion de documents scientifiques de niveau recherche, publiés ou non, émanant des établissements d'enseignement et de recherche français ou étrangers, des laboratoires publics ou privés. 


\section{Effect of dispersed crude oil exposure upon the aerobic metabolic}

\section{scope in juvenile golden grey mullet (Liza aurata)}

Thomas Milinkovitch $^{1 *}$, Julie Lucas ${ }^{1}$, Stéphane Le Floch ${ }^{2}$, Hélène Thomas-Guyon ${ }^{1}$, Christel Lefrançois $^{1}$

\section{Affiliations}

${ }^{1}$ Littoral Environnement et Sociétés (LIENSs), UMR 6250, CNRS-Université de La Rochelle, 2 rue Olympe de Gouges - F-17042 La Rochelle Cedex 01, France. Email:

thomas.milinkovitch01@univ-lr.fr; christel.lefrancois@univ-lr.fr; helene.thomas@univ-lr.fr; julie.lucas@univ-lr.fr.

${ }^{2}$ Centre de Documentation, de Recherche et d'Expérimentations sur les Pollutions Accidentelles des Eaux (CEDRE), 715 rue Alain Colas, CS41836-F- 29218 Brest Cedex 2, France. Email: stephane.le.floch@ cedre.fr

* Correspondingauthor: Thomas Milinkovitch

Littoral Environnement et Sociétés (LIENSs)

UMR 6250, CNRS-Université de La Rochelle

2 rue Olympe de Gouges

F-17042 La Rochelle Cedex 01, France

Email: thomas.milinkovitch01@univ-lr.fr

Tel: $+33(0) 546457217$

Fax: +33 (0)546458264

Abbreviations: BAL: Brut Arabian Light; C: Control; CD: Chemically Dispersed oil using dispersant; D: Dispersant solution; MD: Mechanically Dispersed oil; WSF: Water Soluble Fraction 


\begin{abstract}
This study evaluated the toxicity of dispersant application which is, in nearshore area, a controversial response technique to oil spill. Through an experimental approach with juveniles of Liza aurata, the toxicity of five exposure conditions was evaluated: (i) a chemically dispersed oil simulating dispersant application; (ii) a single dispersant as an internal control of chemically dispersed oil; (iii) a mechanically dispersed oil simulating natural dispersion of oil; (iv) a water soluble fraction of oil simulating an undispersed and untreated oil slick and (v) uncontaminated sea water as a control exposure condition. The relative concentration of PAHs (polycyclic aromatic hydrocarbons) biliary metabolites showed that the incorporation of these toxic compounds was increased if the oil was dispersed, whether mechanically or chemically. However, toxicity was not observed at the organism level since the aerobic metabolic scope and the critical swimming speed of exposed fish were not impaired.
\end{abstract}

Key words: Dispersant toxicity, Aerobic metabolic scope, Critical swimming speed, biliary metabolites, nearshore area, golden grey mullet.

\title{
I. Introduction
}

Over the past decades, oil spills have become a common occurrence; e.g. Amoco Cadiz in 1978, Erika in 1999, Prestige in 2002 and recently the Deepwater Horizon platform (2010). Nowadays, recovery and dispersion are the two mains techniques used to clean up an oil spill. 
Recovery is based on an efficient containment of the oil slick and is therefore conducted when the oil is viscous, the water temperature low, and the sea surface flat (Merlin, 2005). On the other hand, dispersant application is operated if the oil is light, the water temperature high, and the sea rough enough to allow dispersion of the oil slick (Chapman et al., 2007). The dispersants used are surfactants (i.e. surface active agents) with a chemical affinity for both oil and water, enabling the petroleum to be mixed into the water column in small mixed oilsurfactant micelles (i.e. with a diameter lower than $100 \mu \mathrm{m}$ ) as described by Canevari (1978). By diluting the oil slick in the water column, dispersants prevent the arrival of the petroleum slick in ecologically sensitive nearshore habitats and reduce the risk of contamination in sea surface-dwelling organisms (e.g. seabirds, marine mammals). Moreover, by increasing the surface-to-volume ratio of the oil, dispersion of the slick accelerates bacterial degradation of hydrocarbons (Thiem, 1994; Churchill et al., 1995; Swannell and Daniel, 1999). In spite of these advantages, dispersant spraying may be considered as a controversial measure in nearshore areas. Indeed, because of the limited dilution potential of the oil in shallow waters, dispersant use may induce high concentrations of petroleum in the water column and thereby raises the toxicity for aquatic organisms. Thus, in order to provide a framework for dispersant use policies in nearshore areas, specific investigation are needed to evaluate the toxicity of its application. In past studies, the toxicity of the dispersant spraying technique was determined by evaluating the mortality of organisms exposed to a single dispersant solution (e.g. Perkins et al., 1973 inSoleasolea). More recent studies took into consideration the toxicity induced by the interaction between the dispersant and the petroleum, such as Lin et al. (2009) and Jung et al. (2009) in juvenile Onchorhyncustshawytscha and Sebastesschlegeli, respectively. These recent studies considered the toxicity of the chemically enhanced water accommodated fractions (CEWAF, described in Singer et al., 2000) : contamination solutions which did not contain the vast quantities of oil droplets formed in situ during the dispersion of an oil slick. 
However, oil droplets (i) have been suggested as a determinant of dispersed oil toxicity by Brannon et al. (2006) and (ii) are particularly present in nearshore areas because of the mechanical agitation due to natural mixing processes (e.g. waves). Therefore, the present study is based on an experimental approach which takes into consideration the presence of these droplets in the water column in order to assess the actual toxicity of dispersant use in nearshore areas. Juvenile golden grey mullets (Liza aurata), a nearshore teleost species, were exposed to (i) Chemically Dispersed oil (CD) simulating dispersant application; (ii) Dispersant alone (D) as an internal control of CD; (iii) Mechanically Dispersed oil (MD) simulating natural dispersion of oil; (iv) Water Soluble Fraction of oil (WSF) simulating an undispersed and untreated oil slick and (v) uncontaminated sea water as a Control exposure condition (C).

For each condition, the level of exposure was evaluated through the concentration in seawater of total petroleum hydrocarbons (TPH) and through the concentration of the 16 priority pollutant Polycyclic Aromatic Hydrocarbons (PAH) listed by US EPA. In parallel, the concentration in the gallbladder of three biliary metabolites was estimated in order to provide information on PAH bioavailability. In addition, the contamination-related impairments were evaluated at the organism level by assessing the fish Aerobic Metabolic Scope (AMS, Fry, 1947). AMS is the difference between Active Metabolic Rate (AMR) and Standard Metabolic Rate (SMR), i.e. the maximal metabolic rate of an organism in a highly active state minus its metabolic rate when at rest (Fry, 1971). Thus, AMS estimates the instantaneous metabolism rate an organism may allocate to its energy-demanding activities (e.g. locomotion, digestion, feeding): AMS is, therefore, claimed to be a relevant proxy of fitness (e.g. Claireaux and Lefrançois, 2007). Environmental factors (e.g. temperature, dissolved oxygen, pollutants) are known to modulate AMS. For instance, in Soleasolea, hypoxia (e.g. 25\% of air saturation) induced a decrease of Active Metabolic Rate (AMR) leading to a decrease of AMS 
(Lefrançois and Claireaux, 2003). Specifically to petroleum hydrocarbon exposure, Davoodi and Claireaux (2007) highlighted a 30\% decrease in AMS in Soleasolea. Such a reduction of AMS illustrates a diminished ability to cope with energy demanding activities, which is likely to result in a prioritization of internal energy flow towards short term survival activities to the detriment of somatic and/or gonadic growth (Claireaux and Lefrançois, 2007; Del Toro-Silva et al., 2008; Chabot and Claireaux, 2008). Thus, since (i) AMS is claimed to be a relevant proxy of fitness and since (ii) it is known to be modulated by pollutants, this study considered this biological parameter in order to estimate the impact of dispersant application upon a Liza aurata population.

\section{Material and Methods}

\subsection{Experimental organisms}

Sixty juvenile golden grey mullets (Liza aurata), provided by CommercioPescaNovellame (Srl, Chioggia, Italy), were used in this experiment. The average length of the fish was 147.70 $\pm 0.49 \mathrm{~mm}$ and their average weight was $34.39 \pm 0.50 \mathrm{~g}$ (mean \pm standard error of the mean). Prior to the exposure studies, the fish were acclimatized for at least 3 weeks in 300-1 flowthrough tanks with the following physico-chemical parameters: dissolved oxygen: $91 \pm 2 \%$ air saturation; salinity: $35 \pm 1$; temperature: $15 \pm 0.1{ }^{\circ} \mathrm{C}$ (mean \pm standard error mean). During this period, fish were under natural photoperiod and fed daily with commercial food (Neosupra AL3 from Le Gouessant aquaculture).

\subsection{Pollutants}




\subsubsection{Oil}

An Arabian Crude Oil was selected for this study. Its composition was evaluated by CEDRE (CEntre of Documentation, Research and Experimentation on accidental water pollution, Brest, France), a laboratory certified according to ISO 9001 and ISO 14001. The oil was found to contain $54 \%$ saturated hydrocarbons, $36 \%$ aromatic hydrocarbons and $10 \%$ polar compounds. To simulate the natural behaviour of the oil after its release at sea (i.e. evaporation of light compounds), the oil was experimentally evaporated under atmospheric conditions. The resulting chemical composition of the oil was thereby $54 \%$ saturated hydrocarbons, $34 \%$ aromatic hydrocarbons and $12 \%$ polar compounds and its API (American Petroleum Institute) gravity was 33.

\subsubsection{Dispersants}

A formulation manufactured by Total Fluides was selected for its efficiency. The dispersant was composed of surfactants (blend of anionic and non ionic types) and solvents. It was a third generation dispersant (concentrated surfactant) deemed effective enough (preliminary determined by CEDRE, using the method NF.T.90-345),non-toxic at the concentration recommended by the manufacturer (preliminary determined by CEDRE assessing standard toxicity test: method NF.T.90-349) and biodegradable.

\subsection{Contamination protocol}

The experimental system employed is described in Milinkovitch et al. (2011). In short, it was made of five cylindrical tanks (diameter=1.1 m; height=0.4 m). Each tank comprised a funnel 
connected to a Johnson L450 water pump which maintained a mixture of oil-dispersant droplets throughout the water column. The experimental system was set up in a temperature controlled room $\left(15 \pm 0.1^{\circ} \mathrm{C}\right)$. Five exposure conditions were tested. Prior to preparation of the exposure conditions, all the tanks were filled with 300-1 of uncontaminated seawater provided by Oceanopolis (Brest, France). The control exposure condition was set up using seawater alone. The chemically dispersed (CD) oil exposure medium was made by pouring 20 $\mathrm{g}$ of petroleum and $1 \mathrm{~g}$ of dispersant into the funnel of the experimental system. The dispersant alone (D), as a positive control of $\mathrm{CD}$, was made by pouring $1 \mathrm{~g}$ of dispersant into the funnel. The mechanically dispersed (MD) oil exposure medium was produced by pouring $20 \mathrm{~g}$ of petroleum into this funnel. For water-soluble fraction (WSF) a $20 \mathrm{~g}$ oil slick was contained using a plastic circle placed on the surface of the seawater. The funnel and the pump were only kept to maintain the same experimental conditions as for the other treatments. The oil slick remained at the surface without mixing and the fish were thereby only exposed to the soluble fraction of the oil.

For each exposure condition, 6 replicates of exposure were successively conducted. Two fish were exposed per replicate so that 12 fish were exposed to each of the five conditions. For each replicate, exposure lasted $48 \mathrm{~h}$. Between consecutive exposures, the experimental tanks were cleaned using dichloromethane (Carlo ErbaReactifs, SDS, France), 12 hour evaporation phase was then conducted and tanks were finally thoroughly washed with freshwater. The absence of traces of dichloromethane was ensured by conducting gas chromatography-mass spectrometry. The fish were starved for $48 \mathrm{~h}$ prior to the bioassays and throughout the exposure period in order to avoid bile evacuation from the gallblader. Physicochemical parameters remained stable (Table 1). No fish died during the all experiment.

\subsection{Chemical analyses}




\subsubsection{Total petroleum hydrocarbon (TPH) seawater concentrations}

TPH concentrations were measured for the 6 replicates of each exposure condition. For each replicate, three samples were made at the beginning $(T=0 h)$ and at the end $(T=48 \mathrm{~h})$ of fish exposure. The mean of the three samples was considered representative of the TPH concentration at each time point. Extraction of samples was conducted with $10 \mathrm{ml}$ of pestipurquality dichloromethane (Carlo ErbaReactifs, SDS, France) which induced separation of the organic and aqueous phases. Then, water was extracted two additional times with the same volume of dichloromethane $(2 \times 10 \mathrm{ml})$. The extracts were dried using anhydrous sulphate and then treated using a UV spectrophotometer (UV-Vis spectrophotometer, Unicam, USA) at $390 \mathrm{~nm}$ as described by Fusey and Oudot (1976). According to CEDRE and taking into account the accuracy of the spectrophotometer (CEDRE property), results obtained with this method are not reliable below $1 \mathrm{mg} / \mathrm{L}$.

\subsubsection{Polycyclic aromatic hydrocarbon (PAH) seawater concentrations}

Two replicates were analyzed at the beginning $(\mathrm{T}=0 \mathrm{~h})$ and end $(\mathrm{T}=48 \mathrm{~h})$ of fish exposure for each replicate. Sixteen PAHs (alkylated and parents), listed by US EPA as priority pollutants, were quantified according to the method described by Roy et al. (2005). After sampling, a 24hour settling phase to separate oil droplets and particulate matter from the seawater was conducted. Then, $150 \mu \mathrm{L}$ of a solution of five perdeuterated internal standards in acetonitrile (Naphthalene $\mathrm{d}_{8}$, Biphenyl $\mathrm{d}_{10}$, Phenanthrene $\mathrm{d}_{10}$, Chrysene $\mathrm{d}_{12}$, and Benzo[a]pyrene $\mathrm{d}_{12}$ at respective concentrations of 210, 110, 210, 40 and $40 \mu \mathrm{g} / \mathrm{mL}$, Sigma-Aldrich, France) were diluted in $10 \mathrm{ml}$ of absolute methanol (Sigma-Aldrich, France) and the resulting solution was added to the liquid phase of samples. Using the stir bar sorptive extraction technique (SBSE - 
Stir bar coated with PDMS, Gerstel, USA) and thermal desorption coupled to capillary gas chromatography-mass spectrometry (GC-MS), the PAHs were extracted from the seawater and treated. The GC was a HP7890 series II (Hewlett Packard, Palo Alto, CA, USA) coupled with a HP5979 mass selective detector (MSD) (Electronic Impact: 70eV, voltage: 2,000 V). According to the procedure of Roy et al. (2005), the quantification limit for each PAH was 1 ng/L.

2.5 Evaluation of aerobic metabolic scope and critical swimming speed

\subsubsection{Experimental set-up}

Two identical swimming tunnels (LoligoApS., Denmark) were employed to challenge simultaneously two fish of each exposure replicates. Swimming tunnel allowed controlling fish activity and measuring the associated oxygen consumption. The swimming tunnels were adapted from those used in Vagner et al. (2008), although were smaller in size (75 1 instead of 150 1). Each swimming tunnel was composed of a swimming respirometer (11 1) and a buffer tank. The swimming respirometer was made of a chamber $(40 \times 10 \times 10 \mathrm{~cm})$ where the fish was placed to be tested. The water flow was generated by a motor fitted with a three bladedpropeller. Some deflectors and a plastic honeycomb promoted rectilinear flow with a uniform velocity profile (vertical and horizontal). A peristaltic pump created a continuous water flow from the respirometer to a flow-through cell oxygen microsensor (Presens, Germany). This oxygen probe was connected to an oxymeter (Microx, Presens, Germany) which was interfaced to a computer via a RS232 port. A data acquisition program (Oxyview) was used to record oxygen saturation every ten seconds. The buffer tank, where temperature and oxygen were controlled using a thermoregulator and an air pump respectively, was connected to the 
swimming respirometer via a flush pump which allowed exchange of water between the two compartments. This water flow renewed oxygen between consecutive measurements and also maintained a constant temperature in the swimming respirometer.

\subsubsection{Experimental protocol}

At the end of the $48 \mathrm{~h}$ contamination period, the fish were gently caught and their fork length (L) was measured before introducing them into the swimming respirometer where they recovered for one night prior to the swim challenge. During the recovery period, the water flow was maintained at a low swimming speed of $0.5 \mathrm{~L} . \mathrm{s}^{-1}$. When the experiment started, water flow was increased by steps of $1.5{\mathrm{~L} . \mathrm{s}^{-1}}^{-1}$ rom 0.5 to $3.5 \mathrm{~L} . \mathrm{s}^{-1}$, and steps of $0.75 \mathrm{~L} . \mathrm{s}^{-1}$ for further increase. The increment duration was $20 \mathrm{~min}$. The fish was considered fatigued if it did not manage to swim against the current and fell against the grid at the rear of the swimming chamber. Then the experiment was stopped and the speed was decreased to 0.5 L.s ${ }^{-1}$. The fish were allowed to recover for a couple of hours before being removed from the swimming respirometer and euthanized using $2 \mathrm{ml}$ of eugenol (99\%, Sigma Aldricht chemicals, France) in $5 \mathrm{ml}$ of seawater. The gallbladder was removed for PAH biliary metabolite analysis. The fish length, mass, width and height were measured. The net oxygen consumption (i.e. the microbial oxygen consumption) was measured to be further subtracted from the measured oxygen consumption.

\subsubsection{Calculations}

2.5.3.1 Oxygen consumption $\left(\mathrm{MO}_{2}\right)$ 
Oxygen consumption $\mathrm{MO}_{2 \text { (meas) }}$ is expressed in $\mathrm{mgO}_{2} \cdot \mathrm{kg}^{-1} \cdot \mathrm{h}^{-1}$ and calculated using the following formula:

$\mathrm{MO}_{2(\text { meas })}=\Delta\left[\mathrm{O}_{2}\right] \cdot \Delta \mathrm{t}^{-1} \cdot \mathrm{V} \cdot \mathrm{M}_{\text {meas }}^{-1}$

where $\Delta\left[\mathrm{O}_{2}\right]$ in $\mathrm{mgO}_{2} \cdot \mathrm{l}^{-1}$ is the variation in oxygen concentration during the measurement period ( $\Delta \mathrm{t}$ in hours), $\mathrm{V}(\mathrm{L})$ is the volume of the respirometer minus the volume of the fish, $\mathrm{M}_{\text {meas }}(\mathrm{kg})$ is the fish mass.

Since an allometric relation exists between oxygen consumption and body mass, $\mathrm{MO}_{2 \text { (meas) }}$ was corrected using the following formula:

$\mathrm{MO}_{2 \text { cor }}=\mathrm{MO}_{2 \text { meas }} \cdot\left(\mathrm{M}_{\text {meas }} \cdot \mathrm{M}_{\text {cor }}{ }^{-1}\right)^{1-\mathrm{A}}$

where $\mathrm{MO}_{2 \mathrm{cor}}\left(\mathrm{mgO}_{2} \cdot \mathrm{kg}^{-1} \cdot \mathrm{h}^{-1}\right)$ is the oxygen consumption related to a standard fish of $0.1 \mathrm{~kg}$ $\left(\mathrm{M}_{\text {cor }}\right)$ fish, $\mathrm{MO}_{2 \text { meas }}\left(\mathrm{mgO}_{2} \cdot \mathrm{kg}^{-1} \cdot \mathrm{h}^{-1}\right)$ is the oxygen consumption calculated for experimented fish whose mass was $\mathrm{M}_{\text {meas }}(\mathrm{kg})$ and $\mathrm{A}$ is the allometric constant describing the relation between oxygen consumption and body mass. In the case of this study, we used $A=0.8$ as employed by Vagner et al. (2008) in the flathead grey mullet (Mugilcephalus).

2.5.3.2 Critical swimming speed $\left(\mathrm{U}_{\text {crit }}\right)$

The critical swimming speedis expressed in L.s ${ }^{-1}$ and calculated using the Brett formula (1964):

$\mathrm{U}_{\text {crit }}=\mathrm{U}_{\mathrm{t}}+\mathrm{t}_{1} \cdot \mathrm{t}^{-1} \cdot \mathrm{U}_{1}$ 
where $U_{t}\left(\mathrm{~L} . s^{-1}\right)$ is the highest velocity maintained for an entire swimming step, $t_{1}(\mathrm{~min})$ is the amount of time spent at the fatigue velocity, $\mathrm{t}(\mathrm{min})$ is the prescribed swimming period (i.e. 20 min in the present study) and $U_{1}$ is the increment velocity $\left(0.75\right.$ or $\left.1.5 \mathrm{~L} . \mathrm{s}^{-1}\right)$.

2.5.3.3 Standard metabolic rate (SMR), active metabolic rate (AMR) and aerobic metabolic scope (AMS)

As expected, oxygen consumption increased exponentially with swimming speed (Brett, 1964) so that SMR can be assessed from the following equation:

$\mathrm{MO}_{2}=\mathrm{SMR} \exp ^{\mathrm{bU}}$

Where SMR is the intercept (i.e. the $\mathrm{MO}_{2}$ when $\mathrm{U}=0 \mathrm{~L} \cdot \mathrm{s}^{-1}$ ), $\mathrm{b}$ is a constant, $\mathrm{U}$ is the swimming speed and $\mathrm{MO}_{2}$ is the oxygen consumption $\left(\mathrm{mgO}_{2} \cdot \mathrm{h}^{-1} \cdot \mathrm{kg}^{-1}\right)$.

AMR is evaluated as the maximum oxygen consumption measured during the swimming test. Finally, AMS is the difference between AMR and SMR. $\mathrm{U}_{\text {crit }}, \mathrm{SMR}$, AMR and AMS were assessed for each fish.

2.6. Fixed wavelength fluorescence analysis

Four $\mu \mathrm{L}$ of bile extracted from the gallbladder of fish were diluted in $996 \mu \mathrm{L}$ of absolute ethanol (VWR International) in quartz cuvettes. Fixed wavelength fluorescence (FF) was then measured on a spectrofluorimeter (SAFAS Flx-Xenius, Monaco). Excitation-emission wavelength pairs $290: 335,341: 383,380: 430$ were employed to detect naphthalene-derived metabolites, pyrene-derived metabolites and benzo[ $[a]$ pyrene-derived metabolites, respectively 
(Aas et al., 2000). The FF values are expressed as arbitrary units of fluorescence and provide an estimation of the relative concentration of metabolites between the five different exposure conditions (C, CD, MD, WSF, D).

\subsection{Statistical analysis}

The statistical analysis was carried out using Statistica software. The homoscedasticity (using the Barlett test) and normality (using the Kolmogorov-Smirnoff test) of data were demonstrated for SMR, AMR, AMS and the fixed wavelength fluorescence. Therefore, for each of these variables, a one-way analysis of variance (one-way ANOVA) was performed in order to test for significant differences due to exposure conditions. For critical swimming speed, homoscedasticity and normality were not respected, therefore a Kruskal-Wallis test was conducted. When necessary, a Tukey post-hoc test was conducted to detect significant differences between exposure conditions. Patterns of TPH and PAH concentrations were analysed using a one-way repeated measure ANOVA with exposure condition as a between factor and time (i.e. at the beginning and at the end of the experiment) as a within factor. When a significant difference was detected, HSD Tukey post hoc test was applied. The results were considered significantly different if $P_{\text {value }}<0.05$. The results were expressed as means \pm standard error means.

\section{Results}

3.1. Total petroleum hydrocarbon (TPH) and polycyclic aromatic hydrocarbon (PAH) concentrations (Table 2). 
Neither TPHs nor PAHs were detected in C and D exposure conditions. TPHs were not detected in WSF exposure conditions while PAHs were detected.

At $\mathrm{T}=0 \mathrm{~h}$, even if $\mathrm{TPH}$ concentrations tended to be higher in $\mathrm{CD}$ than in MD exposure, the results did not differ significantly. At $\mathrm{T}=48 \mathrm{~h}$, the TPH concentration remained stable in $\mathrm{CD}$ while it significantly decreased in MD exposure which resulted in a TPH concentration, at $\mathrm{T}=48 \mathrm{~h}$, significantly lower in the mechanically dispersed oil solution than in the chemically dispersed oil.

At $\mathrm{T}=0 \mathrm{~h}$, the concentrations of $\mathrm{PAHs}$ in $\mathrm{CD}$ and $\mathrm{MD}$ exposure conditions were significantly higher than in WSF. At $\mathrm{T}=48 \mathrm{~h}$, the PAH concentration significantly decreased in $\mathrm{CD}$ and MD exposure, while no significant decrease was observed in WSF. Although not statistically different, the concentration of PAH (at $\mathrm{T}=48 \mathrm{~h}$ ) was higher in MD and CD than in WSF.

Concerning the 16 US EPA PAHs (Table 3), the pattern was similar, whatever the exposure conditions. Naphthalene (alkylated and parents) concentration represented the major proportion of dissolved PAHs. While the concentration of two and three ring compounds (from naphthalene to fluoranthene, Table 3) tended to represent the higher proportion of PAHs dissolved in seawater, heavier PAHs (four rings and more) showed low concentrations. Regarding variation over time, concentrations of two and three ring compounds tended to decrease during exposure contrary to the concentration of heavier PAHs. However, readers must take into account that these results were not statistically tested, due to the high variability between replicates.

\subsection{Fixed wavelength fluorescence analysis (Figure 1)}


Fixed wavelength fluorescence analysis did not reveal any significant differences in the relative concentration of naphthalene derived metabolites between exposure conditions. On the contrary, a significant increase in the relative concentration of pyrene derived metabolites was observed following both MD and CD exposure, when compared to C, D and WSF. The same pattern was obtained for benzo $[a]$ pyrene derived metabolites.

3.3 Aerobic metabolism (Figure 2) and critical swimming speed ( $\mathrm{U}_{\text {crit }}$, Figure 3)

For all conditions of exposure, the increasing swimming speed of the fish induced an exponential increase in oxygen demand (results not shown). This exponential increase in oxygen consumption was followed by a plateau as the fish fatigued. Concerning SMR and AMR (Figure 2), no significant difference was found between exposure conditions. Due to high AMR values, AMS tended to be higher in the Control exposure condition than in contaminant exposure conditions even if no significant difference was found between conditions. $\mathrm{U}_{\text {crit }}$ (Figure 3) showed the same pattern as AMS.

\section{Discussion}

The aim of this study was to assess the toxicity of dispersant use in nearshore areas. Our experimental approach aimed at evaluating the toxicity of dispersant application on an oil slick under mixing processes to simulate turbulent energy that is a characteristic of nearshore areas (e.g. waves) and also an abiotic condition required for dispersant use (Merlin, 2005). 


\subsection{TPH concentration, PAH concentration and relative concentration of biliary metabolites}

Concentrations of TPHs (Table 2) in both CD and MD exposure present the same order of magnitude as the concentrations measured on oil spill sites or field studies. For instance, Cormack (1977) measured concentrations of $18 \mathrm{mg} / \mathrm{L}$ in the top $30 \mathrm{~cm}$ of the water column after chemical dispersion and Spooner (1970) measured $50 \mathrm{mg} / \mathrm{L}$ of naturally dispersed oil after an oil spill in TarutBay (Saudi Arabia). In the present study, the TPH concentration was found to be significantly lower in MD than in $\mathrm{CD}$ at the end of the $48 \mathrm{~h}$ exposure period. This phenomenon was probably due to the petroleum adherence to the experimental system (in particular to the funnel) which was observed for MD exposure but not $\mathrm{CD}$ exposure. This reduction of petroleum adherence due to dispersant has even been discussed in Milinkovitch et al. (2011) and is in accordance with a field study of Baca et al. (2006) in which dispersant permitted to reduce the adherence of petroleum to natural substrate such as sea grasses and corals.

With regards to the kinetics of hydrocarbon concentration and exposure period, our experimental approach was used to expose fish to a possible scenario. Indeed, in most oil spills in offshore areas, TPH concentrations have decreased drastically after 2-5 hours (Lessard and Demarco, 2000) during which a localized oil slick is dispersed and the hydrocarbons are disseminated. On the contrary, in the shallow waters of nearshore areas, the lower dilution potential (due to the size of the water column) is likely to reduce the dissemination speed. Moreover in case of a tanker grounding in coastal areas, the continuous release of oil together with the turbulent mixing process may cause the TPH concentration to be maintained in the water column. For instance, in the case of the Braer oil spill, which 
occurred in rough sea conditions (up to 10 Beaufort), dispersion was maintained for over a week (Lunel, 1995). Our experimental approach exposed fish to a halfway scenario (between a drastic decrease and one week of dispersion) in which the concentration was maintained (for CD exposure) or decreased slowly (for MD exposure) over a $48 \mathrm{~h}$ period.

With regards to the sum of PAH concentrations, a higher concentration was observed for MD and CD exposure than for WSF exposure. This was probably due to the fact that oil droplets (observed for $\mathrm{CD}$ and $\mathrm{MD}$ exposure) have a larger surface/volume ratio than an oil slick, inducing enhanced solubilisation of PAHs. Our results showed that, during the $48 \mathrm{~h}$ exposure, PAH concentration decreased in $\mathrm{MD}$ as well as CD treatments. Regarding to the concentrations of the $16 \mathrm{PAHs,}$ this decrease seems to be due to a loss of the lighter compounds (from naphthalene to phenanthrene) because of their volatilization and/or photolysis as suggested by Huang et al. (2004).

Concerning PAH biliary metabolites, concentrations of pyrene and benzo[a]pyrene type were relatively higher in $\mathrm{MD}$ and $\mathrm{CD}$ than for other exposure conditions (WSF, D, C) which suggests a higher incorporation of these compounds when the oil was dispersed (mechanically and/or chemically). The similar patterns observed for MD and CD exposure suggest that dispersant application did not increase PAH bioavailability. On the other hand, the invariability of naphthalene type metabolites between all the conditions was probably due to the high turnover of light $\mathrm{PAH}$ which were rapidly bioaccumulated (as described in Mytilusedulis in Baussant et al. 2001) and metabolized in the tissues so that metabolites may not have been accumulated in the gallbladder of contaminated fish.

\subsection{Aerobic metabolic scope and critical swimming speed}


Results in this study conform to those observed in the literature (Brett, 1964; Webb, 1975; Vagner et al., 2008). Indeed, in accordance with the literature, the increasing swimming speed induced an exponential elevation in oxygen demand $\left(\mathrm{MO}_{2}\right)$ followed by a plateau when Liza aurata approached $\mathrm{U}_{\text {crit }}$ (data not shown). Moreover, SMR and AMR values obtained in this study for control fish $\left(109 \mathrm{mgO} \cdot \mathrm{kg}^{-1} \cdot \mathrm{h}^{-1}\right.$ and $958 \mathrm{mgO} \cdot \mathrm{kg}^{-1} \cdot \mathrm{h}^{-1}$, respectively) are of the same order of magnitude as the results obtained in Mugilcephalus, a close species tested at $20^{\circ} \mathrm{C}$ (76 and approximately $700 \mathrm{mgO} 2 \cdot \mathrm{kg}^{-1} \cdot \mathrm{h}^{-1}$, respectively, Vagner et al., 2008). The comparison of $U_{\text {crit }}$ values obtained with values observed in literature is limited due to the difference of abiotic and/or biotic experimental parameters (such as temperature, species or size of the fish) which influence the metabolic activity and by the way the swimming performance of the fish. Although precocious biomarkers, such as biliary metabolites, revealed an increase of hydrocarbons exposure due to contamination, measurements of SMR and AMR in Liza aurata did not reveal any differences between exposure conditions leading, as expected, to an unchanged AMS. AMS illustrates the energy an organism is able to mobilize for sustaining activities (Fry, 1971; Priede, 1985; Claireaux and Lefrançois, 2007). With a constant AMS, energy demanding activities such as locomotion, digestion or growth are therefore expected to remain unimpaired in contaminated golden grey mullets. As a consequence, in our study, swimming performance, measured by critical swimming speed, was also not altered by contaminant exposure.

These results are in accordance with results obtained by McKenzie et al. (2007) which suggested that organic pollutants did not affect swimming performance whereas inorganic pollutants such as heavy metals (Wilson et al. 1994 ; Pane et al., 2004) or ammonia (McKenzie et al., 2003) did.

However, in contrast to the results of this study, a study by Davoodi and Claireaux (2007) showed that exposure to petroleum decreased the active metabolic rate of the common sole 
(Soleasolea) while the standard metabolic rate remained unchanged. The same authors (Claireaux et al., 2004 ;Claireaux and Davoodi, 2010) suggested that reduction in AMR could be explained by the impairment of heart rate and stroke volume which led to diminished cardio-respiratory performances, as well as by the alteration of gill functional integrity which reduce oxygen diffusion across the respiratory epithelium and into the blood. Although these studies exposed effects of petroleum upon aerobic metabolism, readers must take into account that the experimental protocol showed a fuel to water ratio which was 76 times higher than in our study. Moreover, unlikely our study, exposure period (5 days), contamination protocol and petroleum composition in these studies did not simulate actual organism exposure during dispersant application.

\section{Conclusion}

Through an experimental approach, this study aimed to assess the toxicity of dispersant application. Although biliary metabolites revealed increased exposure to PAHs following dispersed oil exposure, no effect was highlighted regarding aerobic metabolic scope nor critical swimming speed. This lack of effect may indicate that the fitness of the fish was not impaired (Fry, 1971; Priede, 1985). However, the lack of significance could also be due to the short exposure time employed in order to simulate the toxicity of oil spill: this study focused on the acute toxicity of oil spill but, in nearshore areas, the contamination of the sediment and the consequent retention of heavy PAHs also induce chronic exposure. Thus, an approach considering the long term toxicity of dispersant use would be relevant in order to give supplementary information concerning the environmental risk of this response technique. 


\section{Acknowledgements}

This study was supported by a $\mathrm{PhD}$ grant from the ConseilGénéral of Charente-Maritime. Special thanks go to Sophie Vanganse and Michel Prineau for her help and assistance during the study. For providing the swimming tunnel, authors acknowledge the IAMC (Istituto per l'Ambiente Marino Costiero) and especially Paolo Domenici. The AgenceNationale de la Recherche and especially Michel Girin and Gilbert Le Lann are acknowledged for financial support for the project 'DISCOBIOL'. The authors also acknowledge Total Fluides and Innospech for providing chemicals.

\section{References}

Aas, E., Baussant, T., Balk, L., Liewenborg, B., Andersen, O. K., 2000. PAH metabolites in bile, cytochrome P4501A and DNA adducts as environmental risk parameters for chronic oil exposure: a laboratory experiment with Atlantic cod. Aquat.Toxicol. 51, 241-258.

Baca, B., Ward, G. A., Lane, C. H., Schuler, P. A., 2005. Net Environmental Benefit Analysis (NEBA) of dispersed oil on nearshore tropical ecosystems derived from the 20 year "TROPICS" field study. Proceedings of the 2005 International Oil Spill Conference, pp. 1-4. Miami, Florida, USA.

Baussant, T., Sanni, S., Jonsson, G., Skadsheim, A., Borseth, J. F., 2001. Bioaccumulation of polycyclic aromatic compounds: 1. Bioconcentration in two marine species and in semipermeable membrane devices during chronic exposure to dispersed crude oil. Environ. Toxicol.Chemistry. 20, 1175-1184.

Brannon, E. L., Collins, K. M., Brown, J. S., Neff, J. M., Parker, K. R., Stubblefield, W. A., 2006. Toxicity of weathered Exxon Valdez crude oil to Pink salmon embryos. Environ. Toxicol.Chemistry. 25, 962-972. 
Brett, J. R., 1964. The respiratory metabolism and swimming performance of young Sockeye salmon. J. Fisheries Res. Board of Canada. 21, 1183-1226.

Canevari, G. P., 1978. Some observations on the mechanism and chemistry aspects of chemical dispersion.Chemicals dispersants for the control of oil spills (eds L. T. J. Mccarthy, G. P. Lindblom\& H. F. Walter), pp. 2-5. American society for testing and materials, Philadelphia.

Chabot, D., Claireaux, G., 2008. Environmental hypoxia as a metabolic constraint on fish: The case of Atlantic cod, Gadusmorhua. Mar. Pollut. Bull. 57, 287-294.

Chapman, H., Purnell, K., Law, R. J., Kirby, M. F., 2007. The use of chemical dispersants to combat oil spills at sea: A review of practice and research needs in Europe. Mar. Pollut. Bull. $54,827-838$.

Churchill, P. F., Dudley, R. J., Churchill, S. A., 1995. Surfactant-enhanced bioremediation.Waste Management. 15, 371-377.

Claireaux, G., Désaunay, Y., Akcha, F., Aupérin, B., Bocquené, G., Budzinski, H., Cravedi, J.-P., Davoodi, F., Galois, R., Gilliers, C., Goanvec, C., Guérault, D., Imbert, N., Mazéas, O., Nonnotte, G., Nonnotte, L., Prunet, P., Sebert, P., Véttier, A., 2004. Influence of oil exposure on the physiology and ecology of the common sole Soleasolea (L.): experimental and field approaches. Aquat.Living Resources. 17, 335-352.

Claireaux, G., Lefrançois, C., 2007. Linking environmental variability and fish performance: integration through the concept of metabolic scope for activity. Phil. Transactions of the Royal Society of London B: Biological Sciences. 362, 2031-2041.

Claireaux, G., Davoodi, F., 2010.Effect of exposure to petroleum hydrocarbons upon cardiorespiratory function in the Common sole (Soleasolea).Aquat.Toxicol. 98, 113-119.

Cormack, D., 1977. Oil pollution.Chemistry and Industry. 14, 605-608. 
Davoodi, F., Claireaux, G., 2007.Effects of exposure to petroleum hydrocarbons upon the metabolism of the Common sole Soleasolea. Mar. Pollut. Bull. 54, 928-934.

Del Toro-Silva, F. M., Miller, J. M., Taylor, J. C., Ellis, T. A., 2008. Influence of oxygen and temperature on growth and metabolic performance of Paralichthyslethostigma (Pleuronectiformes: Paralichthyidae). J. Experiment. Mar. Biol. Ecol. 358, 113-123.

Fry, F. E. J., 1947. Effect of the environment on animal activity.University of Toronto Press, Toronto. pp. 62.

Fry, F.E., 1971. The effect of environmental factors on the physiology of fish. In: Hoar, W.S., Randall, D.J. (Eds.), Fish Physiology, vol. VI. Academic Press, NY, S. Francisco, London, pp. 1-98

Fusey, P., Oudot, J., 1976.Comparaison de deux méthodes d'évaluation de la biodégradation des hydrocarbures in vitro. Material und Organismen (Berlin). 4, 241-251.

Huang, R., Choe, E., Min, D. B., 2004. Effects of riboflavin photosensitized oxidation on the volatile compounds of soymilk. J. Food Sci. 69, 733-738.

Jung, J. H., Yim, U. H., Han, G. M., Shim, W. J., 2009. Biochemical changes in rockfish, Sebastesschlegeli, exposed to dispersed crude oil. Comparative Biochem. Physiol. Part C: Toxicology \& Pharmacology. 150. 218-223.

Lefrançois, C., Claireaux, G., 2003. Influence of ambient oxygenation and temperature on metabolic scope and scope for heart rate in the Common sole Soleasolea. Mar. ecol. progress series. 259, 273-284.

Lessard, R. R., DeMarco, G., 2000. The significance of oil spill dispersants. Spill Sci. Technol. Bull. 6, 59-68.

Lin, C. Y., Anderson, B. S., Phillips, B. M., Peng, A. C., Clark, S., Voorhees, J., Wu, H.-D.I., Martin, M. J., McCall, J., Todd, C. R., Hsieh, F., Crane, D., Viant, M. R., Sowby, M. L., 
Tjeerdema, R. S., 2009. Characterization of the metabolic actions of crude versus dispersed oil in salmon smolts via NMR-based metabolomics. Aquat.Toxicol. 95, 230-238.

Lunel, T., 1995. The Braer oil spill: oil fate governed by dispersion. Proceedings of the 1995 International Oil Spill Conference.Long Beach, California, USA.

McKenzie, D.J., Shingles, A., Taylor, E.W., 2003. Sub-lethal plasma ammonia accumulation and the swimming performance of salmonids.Comparative Biochem. Physiol. 135, 515-526.

McKenzie, D.J., Garofalo, E., Winter, M.J., Verweij, F., Ceradini, S., Day, N., Van der oost, R., Butler, P.J., Chipman, J.K., Taylor, E.W., 2007. Complex physiological traits as biomarkers of the sub-lethal toxicological effects of pollutants exposure in fishes.Phil. Transaction Royal Society B. 362, 2043-2059.

Merlin, F. X., 2005. Traitement aux dispersants des nappes de pétrole en mer. pp. 54. CEDRE, Brest.

Milinkovitch, T., Ndiaye, A., Sanchez, W., Le Floch, S., Thomas-Guyon, H., 2011. Liver antioxidant and plasma immune responses in juvenile Golden grey mullet (Liza aurata) exposed to dispersed crude oil. Aquat. Toxicol. 101, 155-154.

Pane, E. F., Haque, A., Goss, G. G., Wood, C. M., 2004. The physiological consequences of exposure to chronic, sublethal waterborne nickel in Rainbow trout (Oncorhynchusmykiss): exercise vs resting physiology. J. Experiment. Biol. 207, 1249-1261.

Perkins, E. J., Gribbon, E., Logan, J. W. M., 1973. Oil dispersant toxicity. Mar. Pollut. Bull. 4, 90-93.

Priede, I. G., 1985. Metabolic scope in fish. In Fish energetics: new perspectives (eds P. Tyler \& P. Calow), pp. 33-64. London, UK: Croom Helm. 
Roméo, M., Cosson, R. P., Gnassia-Barelli, M., Risso, C., Stien, X., Lafaurie, M., 1997. Metallothionein determination in the liver of the Sea bass Dicentrarchuslabrax treated with copper and B(a)P. Mar. Environ. Res. 44, 275-284.

Roy, G., Vuillemin, R., Guyomarch, J., 2005. On-site determination of polynuclear aromatic hydrocarbons in seawater by stir bar sorptive extraction (SBSE) and thermal desorption GCMS. Talanta, 66, 540-546.

Singer, M. M., Aurand, D., Bragin, G. E., Clark, J. R., Coelho, G. M., Sowby, M. L., Tjeerdema, R. S., 2000. Standardization of the preparation and quantitation of wateraccommodated fractions of petroleum for toxicity testing. Mar. Pollut. Bull. 40, 1007-1016.

Spooner, M. F., 1970.Oil spill in Tarut Bay, Saudi Arabia.MarPollut.Bull. 1, 166-167.

Swannell, R. P. J., Daniel, F., 1999.Effect of dispersants on oil biodegradation under simulated marine conditions.Proceedings of the 1999 International Oil Spill Conference. pp. 169-176. Seattle, Washington, USA.

Thiem, A., 1994. Degradation of polycyclic aromatic hydrocarbons in the presence of synthetic surfactants.Applied and EnvironmentMicrobiology. 60, 258-263.

Vagner, M., Lefrançois, C., Ferrari, R. S., Satta, A., Domenici, P., 2008. The effect of acute hypoxia on swimming stamina at optimal swimming speed in Flathead grey mullet Mugilcephalus. J. Mar. Biol. 155, 183-190.

Webb, P.W., 1975. Hydrodynamics and energetics of fish propulsion.Bull. Fish.Res. Bd Can.190, 159.

Wilson, R. W., Bergman, H. L., Wood, C. M., 1994. Metabolic costs and physiological consequences of acclimation to aluminium in juvenile Rainbow trout (Oncorhynchusmykiss).Acclimation specificity, resting physiology, feeding, and growth.Canadian J. Fisheries and Aquat. Sci. 51, 527-535.

Table 1: Physicochemical Parameters Monitored over the Experimental Period. Values are the mean of six tank replicates ( \pm standard error mean). AS = air saturation 


\begin{tabular}{cccc}
\hline & Temperature $\left({ }^{\circ} \mathrm{C}\right)$ & Oxygen $(\% \mathrm{AS})$ & $\mathrm{pH}$ \\
\hline \hline $\mathrm{C}$ & $14.39 \pm 0.15$ & $99.64 \pm 1.4$ & $8.05 \pm 0.01$ \\
$\mathrm{CD}$ & $14.49 \pm 0.13$ & $99.47 \pm 1.6$ & $7.98 \pm 0.02$ \\
$\mathrm{MD}$ & $14.68 \pm 0.11$ & $100.71 \pm 2.0$ & $8.03 \pm 0.03$ \\
$\mathrm{WSF}$ & $14.57 \pm 0.13$ & $98.13 \pm 3.2$ & $8.02 \pm 0.03$ \\
$\mathrm{D}$ & $14.46 \pm 0.12$ & $99.55 \pm 1.5$ & $8.03 \pm 0.02$ \\
\hline
\end{tabular}

Table 2: TPH concentration and concentration of the sum of 16 parents and alkylated USEPA PAH ( $\Sigma \mathrm{PAH})$ in the five treatments at the beginning $(\mathrm{T}=0 \mathrm{~h})$ and at the end of the exposure ( $\mathrm{T}=48 \mathrm{~h}$ ) for $\mathrm{C}$ (Control), CD (Chemically Dispersed oil), MD (Mechanically Dispersed oil), WSF (Water Soluble Fraction of oil) and D (Dispersant). For each contaminant measurements (TPH and PAH),different letters in the same row indicate significant difference of concentration between $\mathrm{T}=0 \mathrm{~h}$ and $\mathrm{T}=48 \mathrm{~h}(\mathrm{p}<0.05)$; different symbols in the same column indicate significant difference of concentration between exposure conditions $(\mathrm{p}<0.05)$. Values are the mean of six tank replicates $( \pm$ standard error mean). n.d. means non detected PAH or TPH compounds

\begin{tabular}{|c|c|c|c|c|}
\cline { 2 - 5 } \multicolumn{1}{c|}{} & $\begin{array}{c}{[\mathrm{TPH}]_{\mathrm{T}=0 \mathrm{~h}}} \\
(\mathrm{mg} / \mathrm{L})\end{array}$ & $\begin{array}{c}{[\mathrm{TPH}]_{\mathrm{T}=48 \mathrm{~h}}} \\
(\mathrm{mg} / \mathrm{L})\end{array}$ & $\begin{array}{c}{[\Sigma \mathrm{PAH}]_{\mathrm{T}=0 \mathrm{~h}}} \\
(\mu \mathrm{g} / \mathrm{L})\end{array}$ & $\begin{array}{c}{[\Sigma \mathrm{PAH}]_{\mathrm{T}=48 \mathrm{~h}}} \\
(\mu \mathrm{L} / \mathrm{L})\end{array}$ \\
\hline C & n.d. & n.d. & n.d. & n.d. \\
\hline CD & $44.0 \pm 3.0^{\mathrm{a}, *}$ & $38.2 \pm 2.8^{\mathrm{a}, *}$ & $60.1 \pm 9.3^{\mathrm{a}, *}$ & $15.6 \pm 3.3^{\mathrm{b}, \uparrow}$ \\
\hline MD & $29.2 \pm 5.6^{\mathrm{a}, *}$ & $14.2 \pm 3.1^{\mathrm{b}, \uparrow}$ & $36.9 \pm 6.3^{\mathrm{a}, *}$ & $1.8 \pm 0.4^{\mathrm{b}, \uparrow}$ \\
\hline WSF & n.d. & n.d. & $3.3 \pm 0.6^{\mathrm{a}, \uparrow}$ & $0.5 \pm 0.1^{\mathrm{a}, \uparrow}$ \\
\hline D & n.d. & n.d. & n.d. & n.d. \\
\hline
\end{tabular}

Table 3: Concentration of 16 parents and alkylated (C1-, C2-,C3-,C4-) US-EPA PAH in sea water during CD (Chemically Dispersed oil), MD (Mechanically Dispersed oil) and WSF 
(Water Soluble Fraction of oil) exposures. Values are the mean of six tank replicates $( \pm$ standard error mean). n.d. means non detected PAH compounds

\begin{tabular}{|c|c|c|c|c|c|c|}
\hline \multirow{3}{*}{$\begin{array}{c}16 \text { US-EPA PAH } \\
\text { (parents and alkylated) }\end{array}$} & \multicolumn{6}{|c|}{ Concentration $(\mathrm{ng} / \mathrm{L})$ at $T=0 \mathrm{~h}$ and $T=48 \mathrm{~h}$} \\
\hline & \multicolumn{3}{|c|}{$\mathbf{T}=\mathbf{0} \mathbf{h}$} & \multicolumn{3}{|c|}{$\mathrm{T}=48 \mathrm{~h}$} \\
\hline & CD & MD & WSF & CD & MD & WSF \\
\hline Naphtalene & $526 \pm 149$ & $676 \pm 191$ & $301 \pm 72$ & $469 \pm 43$ & $71 \pm 16$ & $48 \pm 6$ \\
\hline C1-Naphtalene & $5798 \pm 1064$ & $4451 \pm 1363$ & $1040 \pm 255$ & $1444 \pm 698$ & $150 \pm 37$ & $111 \pm 17$ \\
\hline C2-Naphtalene & $21948 \pm 4808$ & $12553 \pm 3181$ & $833 \pm 167$ & $3641 \pm 1725$ & $167 \pm 35$ & $105 \pm 15$ \\
\hline C3-Naphtalene & $23828 \pm 4195$ & $12398 \pm 2436$ & $497 \pm 181$ & $4276 \pm 1204$ & $156 \pm 26$ & $55 \pm 7$ \\
\hline C4-Naphtalene & $4294 \pm 602$ & $4654 \pm 2441$ & $171 \pm 55$ & $1513 \pm 180$ & $312 \pm 48$ & $23 \pm 4$ \\
\hline Acénaphtylene & $8 \pm 8$ & $9 \pm 7$ & $1 \pm 0$ & $27 \pm 2$ & $1 \pm 0$ & n.d. \\
\hline Acénaphtene & $33 \pm 3$ & $32 \pm 3$ & $3 \pm 0$ & $46 \pm 3$ & $1 \pm 0$ & n.d. \\
\hline Fluorene & $283 \pm 22$ & $202 \pm 12$ & $6 \pm 2$ & $121 \pm 21$ & $2 \pm 1$ & n.d. \\
\hline C1-Fluorene & $370 \pm 39$ & $206 \pm 31$ & $9 \pm 3$ & $169 \pm 22$ & $10 \pm 3$ & $2 \pm 0$ \\
\hline C2-Fluorene & $224 \pm 27$ & $128 \pm 19$ & $7 \pm 2$ & $168 \pm 13$ & $29 \pm 7$ & $2 \pm 1$ \\
\hline C3-Fluorene & $62 \pm 9$ & $27 \pm 10$ & $2 \pm 1$ & $60 \pm 8$ & $29 \pm 4$ & $1 \pm 0$ \\
\hline Phenanthrene & $600 \pm 29$ & $343 \pm 47$ & $18 \pm 4$ & $477 \pm 66$ & $5 \pm 1$ & $5 \pm 2$ \\
\hline Anthracene & $153 \pm 82$ & $47 \pm 42$ & $2 \pm 1$ & $141 \pm 56$ & $2 \pm 0$ & $2 \pm 1$ \\
\hline C1-Phenanthrenes/Anthracene & $868 \pm 45$ & $456 \pm 85$ & $16 \pm 5$ & $591 \pm 122$ & $12 \pm 6$ & $5 \pm 1$ \\
\hline C2-Phenanthrenes/Anthracene & $472 \pm 41$ & $274 \pm 52$ & $22 \pm 9$ & $530 \pm 37$ & $108 \pm 22$ & $4 \pm 1$ \\
\hline C3-Phenanthrenes/Anthracene & $183 \pm 25$ & $104 \pm 24$ & $12 \pm 8$ & $241 \pm 33$ & $107 \pm 15$ & $3 \pm 1$ \\
\hline C4-Phenanthrenes/Anthracene & $4 \pm 3$ & n.d. & $3 \pm 3$ & $3 \pm 4$ & n.d. & $1 \pm 1$ \\
\hline Fluoranthene & $4 \pm 1$ & $10 \pm 8$ & $4 \pm 2$ & $28 \pm 1$ & $2 \pm 1$ & $1 \pm 0$ \\
\hline Pyrene & $10 \pm 1$ & $15 \pm 9$ & $6 \pm 3$ & $31 \pm 1$ & $6 \pm 1$ & $1 \pm 0$ \\
\hline C1-Fluoranthenes/Pyrenes & $17 \pm 5$ & $9 \pm 2$ & n.d. & $26 \pm 4$ & $13 \pm 2$ & n.d. \\
\hline C2-Fluoranthenes/Pyrenes & $29 \pm 8$ & $15 \pm 4$ & $12 \pm 10$ & $48 \pm 7$ & $26 \pm 3$ & n.d. \\
\hline C3-Fluoranthenes/Pyrenes & $27 \pm 8$ & $22 \pm 15$ & $22 \pm 17$ & $42 \pm 8$ & $19 \pm 3$ & $1 \pm 1$ \\
\hline $\operatorname{Benzo}[a]$ anthracene & $3 \pm 0$ & $37 \pm 28$ & $3 \pm 2$ & $130 \pm 38$ & $10 \pm 7$ & $2 \pm 2$ \\
\hline Chrysene & $64 \pm 7$ & $72 \pm 31$ & $11 \pm 5$ & $225 \pm 44$ & $40 \pm 7$ & $7 \pm 4$ \\
\hline Benzo $[b+k]$ fluoranthene & $33 \pm 15$ & $48 \pm 37$ & $15 \pm 6$ & $474 \pm 177$ & $97 \pm 75$ & $51 \pm 47$ \\
\hline Benzo $[a]$ pyrene & $32 \pm 13$ & $17 \pm 11$ & $20 \pm 10$ & $225 \pm 80$ & $87 \pm 61$ & $12 \pm 11$ \\
\hline $\operatorname{Benzo}(g, h, i)$ perylene & $91 \pm 25$ & $46 \pm 24$ & $37 \pm 11$ & $231 \pm 36$ & $123 \pm 65$ & $18 \pm 10$ \\
\hline Indeno $(1,2,3-c d)$ pyrene & $71 \pm 16$ & $29 \pm 8$ & $41 \pm 12$ & $86 \pm 32$ & $105 \pm 71$ & $22 \pm 11$ \\
\hline $\operatorname{Dibenzo}(a, h)$ anthracene & $105 \pm 24$ & $46 \pm 16$ & $56 \pm 17$ & $132 \pm 43$ & $149 \pm 91$ & $33 \pm 17$ \\
\hline
\end{tabular}




\section{Figure captions}

Figure 1: Fixed wavelength fluorescence (FF) of bile reflecting biliary PAHs metabolites levels after $48 \mathrm{~h}$ exposure to Control (C), Chemically Dispersed oil (CD), Mechanically Dispersed oil solution (MD), Water Soluble Fraction (WSF) and Dispersant (D) solution: (a) FF 290:335 (naphthalene derived type of metabolites); (b) FF 341:383 (benzo[a]pyrene type of metabolites); (c) FF 380:430 (pyrene derived type of metabolites). Levels expressed as fluorescence intensity. Values represent mean \pm standard error $(n=10$ per treatment). Bars not sharing common letters indicate asignificant difference, where $\mathrm{P}<0.05$.

Figure 2: Standard metabolic rate (SMR), Active metabolic rate (AMR) and Aerobic metabolic scope (AMS) of golden grey mullets exposed to Control (C), Chemically Dispersed oil (CD), Mechanically Dispersed oil (MD), Water Soluble Fraction (WSF) and Dispersant (D) solution. Results are expressed as mean values ( \pm standard error mean, $n=12$ ). No significant difference was found.

Figure 3: Critical swimming speed ( $\mathrm{U}_{\text {crit }}$ ) of golden grey mullets exposed to Control (C), Chemically Dispersed oil solution (CD), Mechanically Dispersed oil solution (MD), Water Soluble Fraction (WSF) and Dispersant (D) solution. Results are expressed as mean values ( \pm standard error mean, $\mathrm{n}=12$ ). No significant difference was found. 


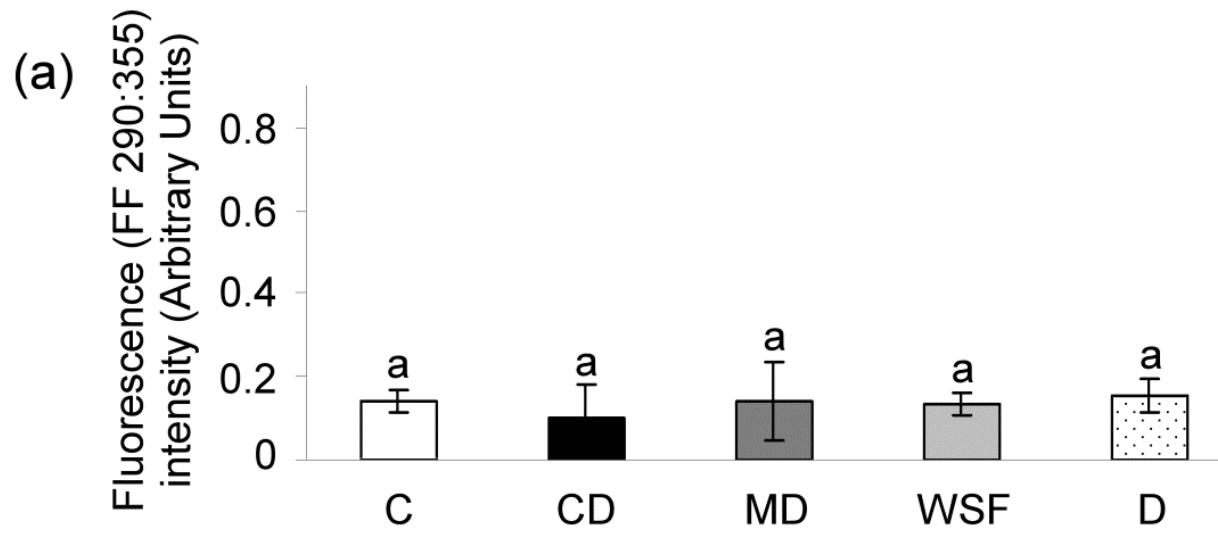

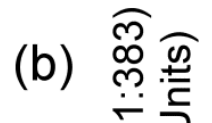

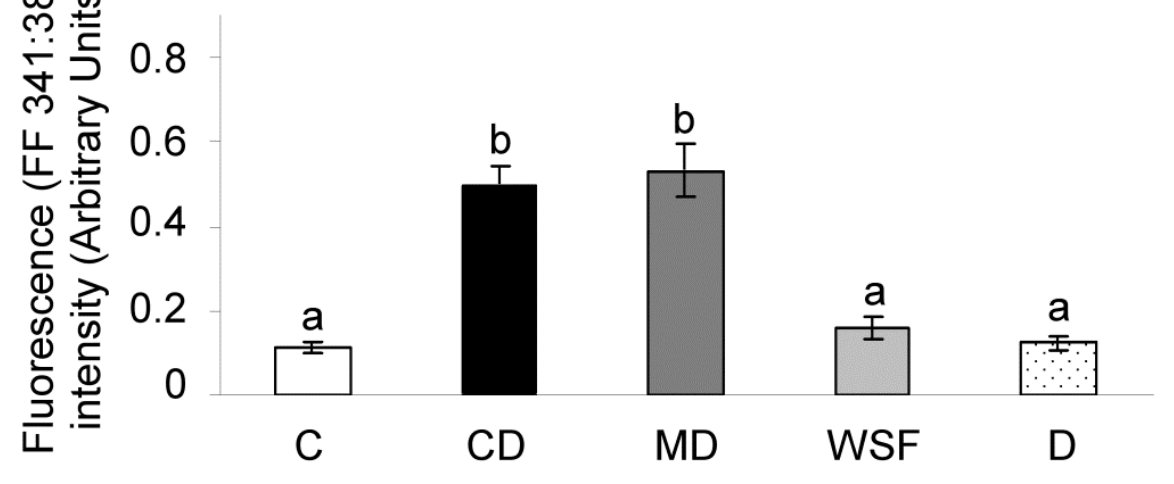

(c) $\stackrel{\widehat{m}}{\leftrightarrow}$

○े 0.8

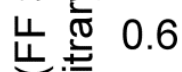

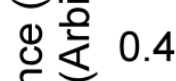

d

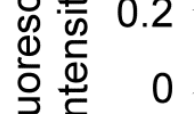

흔.

(

MD WSF

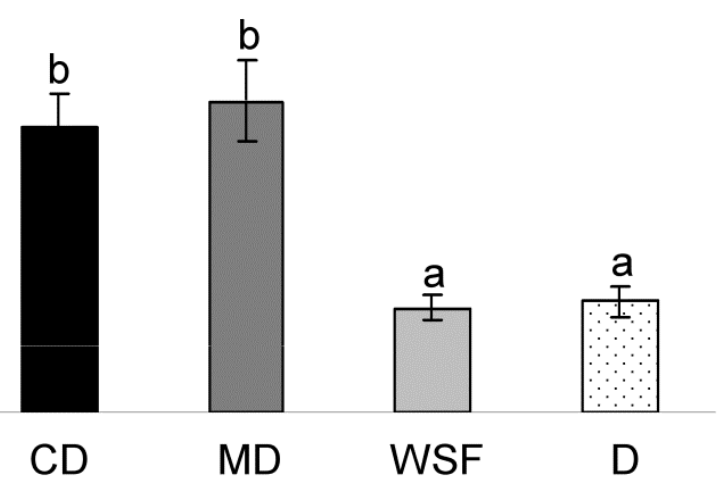



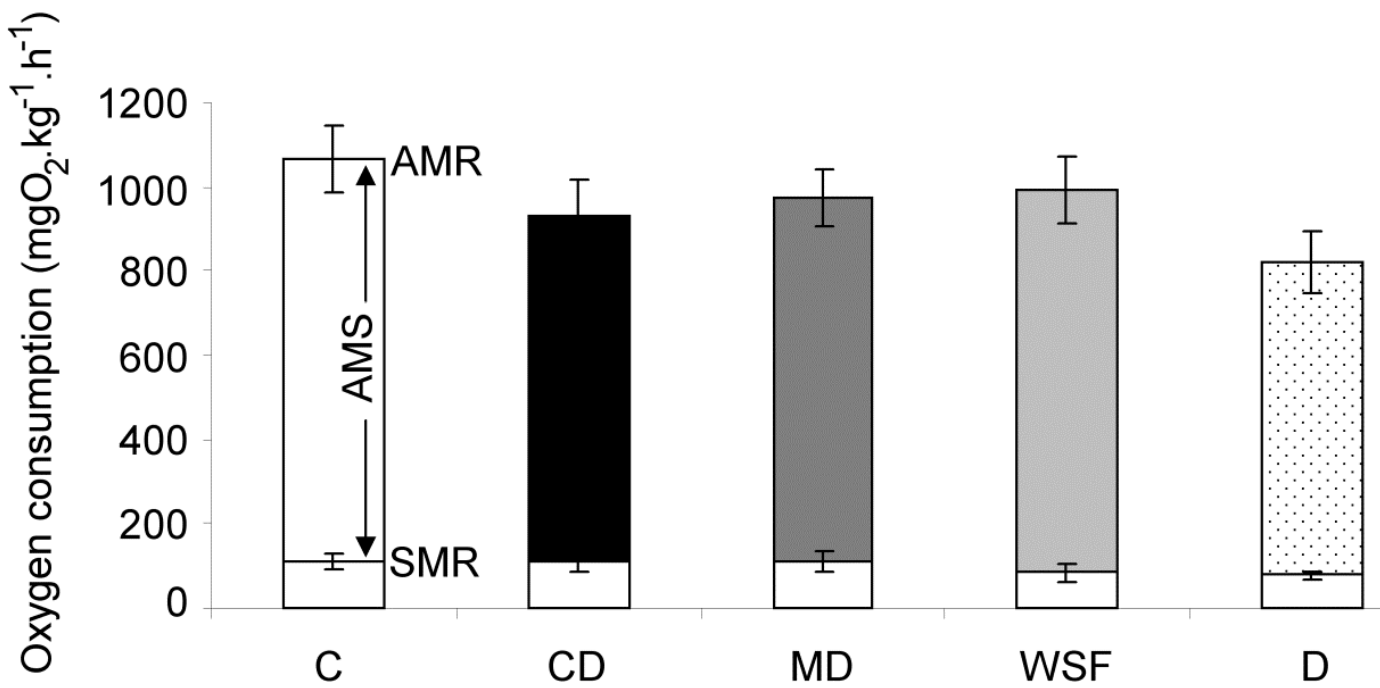

D

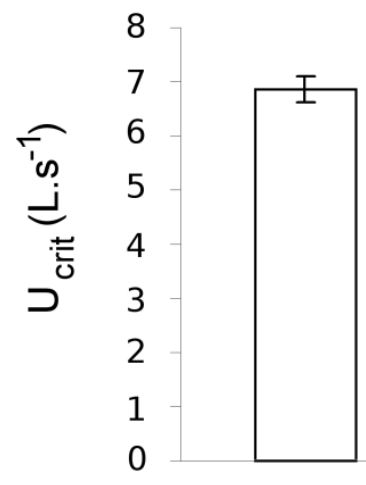

C
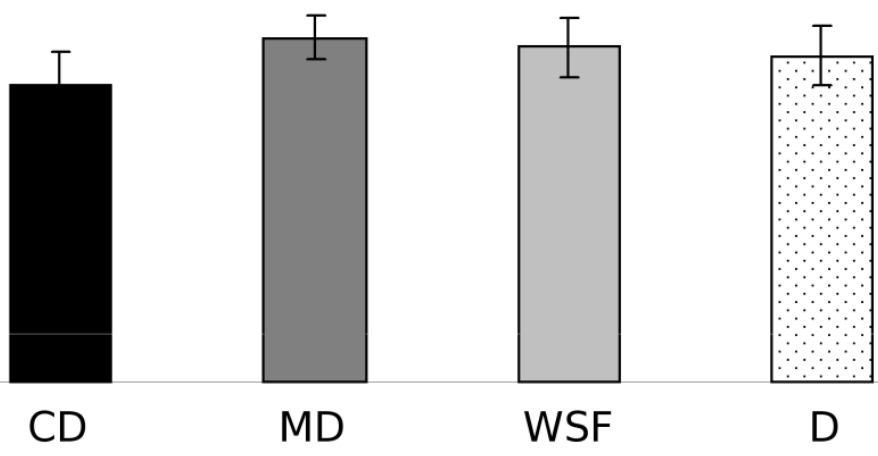